\title{
The Role of Material Goods in Spiritual Development Lin Poyer
}

\begin{abstract}
The problem of materialism is widely recognized as a source of dissatisfaction in industrial civilization. At the same time, mass production and modern technology are also acknowledged as providing desirable standards of health, education, and physical comfort. The challenge is to develop creative, satisfying ways to live within mass production/mass consumption society. Learning to deal appropriately with material goods is important to living in accordance with Bahá'í principles of individual spiritual growth. Understanding the symbolic dimension of goods, through insights from anthropology and psychology, provides us with a way to manage our use of possessions towards this end. Objectification - the process through which physical things are imbued with meaning in a specific sociocultural context-is a key concept in this understanding. Objectification can produce alienation, in the Marxian sense; but, used properly, the capacity of things to carry meaning has the potential to assist individuals in their personal growth. Recognition of the symbolic dimension of objects is particularly critical in enabling individuals to strive for detachment in highly materialistic societies.
\end{abstract}

\begin{abstract}
Résumé
Le problème du matérialisme est largement reconnu comme étant une source d’insatisfaction dans les civilisations industrielles. Par ailleurs, la production de masse et la technologie moderne sont reconnues pour avoir permis d'atteindre un niveau desirable dans les domaines de la santé, de l'éducation et du confort physique. Le défi consiste à trouver des moyens créatifs et satisfaisants pour vivre dans une société de production et de consommation de masse. Il est important d'apprendre à envisager les biens matériels de façon adéquate pour vivre en accord avec les principes bahá'ís de croissance spirituelle. La compréhension de la dimension symbolique des biens, par le biais de l'anthropologie et de la psychologie, nous permet de trouver des moyens d'utiliser nos possessions dans ce but. L'objectivation, soit le processus par lequel on accorde aux objets physiques une signification dans un contexte socio-culturel précis, est un concept clé dans ce contexte. L’objectivation peut être aliénante, dans une perspective marxiste; mais si elle est employée a bon escient, le fait d'imputer une signification à des objets peut potentiellement aider les individus dans leur croissance personnelle. La reconnaissance de la dimension symbolique des objets est particulièrement importante car elle permet aux individus de faire des efforts de détachement dans les sociétés hautement matérialistes.
\end{abstract}

\section{Resumen}

El problema del materialismo es ampliamente reconocido como una fuente de descontento en la civilización industrial. A la misma vez, la producción en masa y la tecnología moderna son tambien reconocidas pues proveen un nivel deseable de salud, educación y comodidad física. El reto es poder desarrollan formas creativas y satisfactorias de vivir en una sociedad de producción y consumo en masa. Aprender a tratar apropiadamente con los productos materiales es importante para vivir de acuerdo con los principios Bahá'ís sobre el crecimiento espiritual individual. Entender las dimensiones simbólicas de los productos, a través de aclaraciones antropológicas y psicologicas, nos provee una manera de manejar nuestras posesiones hacia este fin. Objectificación—el proceso a través del cual las cosas físicas son imbuidas de significados en un contexto especifico socio-cultural—es un concepto clave en este entendimiento. Objectificación puede producir alienación, en el sentido Marxista, pero, usada apropiadamente, la capacidad de los objetos de llevar significado tiene el potencial de ayudar al individuo en su crecimiento personal. El reconocimiento de la dimensión simbólica de los objetos es particularmente crítico en capacitar al individuo a esmerarse por desarrollar el desprendimiento en sociedades sumamente materialistas.

$\mathrm{I}$ t is widely acknowledged that materialism — "the belief that the ultimate goals of personal life can be fulfilled by Lthings and sensations" (Csikszentmihalyi and Rochberg-Halton, Meaning ix) -is a besetting sin of modern Western civilization. In its philosophical form, materialism denies the spiritual reality of humankind and gives primacy to physiological and narrowly behaviorist interpretations of human activity. In its everyday form, materialism pressures citizens of industrialized societies into habits of consumption, status competition, and conformity that are widely recognized as conducive to dissatisfaction and unhappiness.

Despite general criticism of the current state of the relationship of Westerners to their material possessions, there is also widespread affirmation of the advantages of industrial mass production. Certainly the lifestyle of the average western European, North American, or Japanese family is the envy and goal of people in materially poorer nations. Standards of public health, longevity, literacy, personal comfort, and relief from the hardest physical labor are all desirable concomitants of the growth of the same mass society that gives us relentless advertising, degradation of the arts in the mass media, and the excesses of conspicuous consumption.

Both academic and popular pleas for reducing the baleful influences of materialism in industrial cultures 
tend to rely on wishful and impractical scenarios for the future. Daniel Miller, in Material Culture and Mass Consumption, points out that condemnation of the current state of affairs is predictably followed by utopian calls either for individual asceticism or for some form of economic primitivism. Miller provides a scholarly and commonsensical response to these social critics by affirming the dual potential of the vast increase in material production in modern times. On the one hand, we have the materialism, consumerism, and "inauthenticity" of modern culture. On the other, it is equally clear that mass production has produced significant desirable improvements in people's lives. There is no possibility that the nations of the world will retreat from large-scale industrial production, nor are individuals likely to reject the physical and personal benefits of mass consumption. The challenge, then, is to understand the implications of modem industrial society and to learn how to live creatively and "authentically" within it.

In this paper, I will use Miller's starting point: that consumer society will always be with us (for the foreseeable future, at least) and that we had best start learning how to live well in it, instead of simply chronicling its problems. The briefest survey of Bahá'í writings indicates that they have much to contribute to building a framework for authentic, satisfying human life in the context of mass production and mass consumption.

John Hatcher, in The Purpose of Physical Reality, has effectively outlined the Bahá'í understanding of human life in the physical world. The Bahá'í view is that the physical world is a matrix in which the human reality develops spiritual qualities. In effect, the physical world is our schoolroom, our laboratory, our training ground. We live in the temporal world so as to develop our eternal spiritual capacities. This perspective immediately focuses attention on the nature and quality of human action vis-à-vis physical things. The Bahá'í view entails active involvement with the world as a means of spiritual growth. The question is not how to escape the world, but how to manage our action in it so as to promote our spiritual development.

For the purpose of this article, let me narrow the question to: what sort of relationship between person and consumer goods is most productive of this desired end? This is a suitable rephrasing, because, in mass production/mass consumption society, dealings with goods constitute an enormous investment of our time, our concern, and our intellectual and physical capacities. It could be argued that more of our daily lives is taken up with relations with things than with people_-at least in part because our relations with people are inevitably mediated through things (providing for our families, sharing consumption experiences such as restaurant meals, shopping, or movies with friends, giving gifts, employing and being employed).

Exploring the spiritual implications of our dealings with material goods requires us to begin with some general considerations of human social life. Modern studies of the relationship of humans to material goods depend on both symbolic and Marxian approaches. Both sorts of analysis provide tools we can use to integrate Bahá'í understandings of this topic with current scholarly developments.

\section{Goods as Symbols}

In Bahá'í philosophy, each person is a reflection of the attributes of God, with the obligation to develop personal spiritual capacities. Thus we can speak of each person needing to increase his or her capacity for love, kindness, truthfulness, creativity, generosity, and so on. How is this accomplished in practice? While prayer, meditation, and reflection have .essential roles, it is clear in the Bahá'í writings that action in the world is essential to developing desirable attributes. Indeed, as Hatcher demonstrates, the requisite of action in the physical world, for our spiritual growth, explains our very existence.

Action in the world obviously entails involvement with social others and with physical objects. As individuals born into a particular time and place, we experience these as intertwined dimensions of a specific cultural system. Just as our social interactions are shaped by the roles and norms of our culture, so the pattern of our use of material objects is culturally organized. A simple example is the universal practice (in one form or another) of giving gifts. The how, what, when, and why of gift giving is culturally organized to such an extent that ignorance of local rules in this respect is almost certain to create misunderstanding. In the same way, every aspect of the use of material goods-from what distribution of wealth is desirable in a society, to social-group distinctions in house style, food, and leisure pursuits, to the changing parade of fashion in dress and furnishings - is pervaded by specific cultural rules and symbolism.

The first step in understanding human relationships with physical things is to become aware of this symbolic dimension of goods in cultural context. We might think of the objects that surround us as a pattern of messages, a concrete code of significance. We use material goods, as we use speech and action, to communicate with ourselves, our family, our compatriots, and our society at large. ${ }^{1}$ This message-bearing nature of goods is in some cases self-evident: for example, providing food for our family or choosing a wedding gift are straightforward in their symbolism. It is more difficult to recognize, however, that there is a symbolic, meaningful, message-sending aspect to every use of every object that touches our lives. Yet this dimension is intrinsic to humanly used objects, which are produced, consumed, and exchanged in a pervasive cultural (i.e., symbolic) universe.

Explicit attention to the symbolic aspects of the goods that frame our lives produces two useful results. First, it makes our culture visible to us as culture and so it eases the path to detachment (which, in its particular use in Bahá'í contexts, is an important human quality). Second, it creates awareness of the potential spiritual significance of our interaction with the material world. In order to specify the nature of this significance, we need to look at what happens when the spiritual part of the self encounters the symbolic dimension of objects. 


\section{The Process of Objectification}

Objectification is a widely used concept in the social sciences. It is subject to a variety of more or less precise definitions, depending on the topic at hand. Daniel Miller points out that in social criticism the use of the term is generally condemnatory, following Marx's view of objectification as a process leading to alienation. Miller himself returns to Hegel and draws on modern uses of the concept in psychology, to reintroduce objectification (as a potentially positive process) into social theory. For our purposes, a very general understanding of objectification will suffice - an understanding that presents it as potentially either positive or negative in its results.

Once a physical item in a specific cultural and social context is invested with meaning, we can say that it objectifies this meaning for the people involved. It makes the sentiment or abstraction palpable and, hence, manipulable. Because of the peculiar qualities of material goods embedded in a market society (they are visible, tactile, durable, portable, purchasable, exchangeable), goods are peculiarly qualified not only to express meaning but also to embody it. The process of objectification refers not only to the expressive quality of goods (what goods "say") but also to the active role of goods in constructing meaning (what goods "do") for their users and for society at large.

As an example, consider the role of goods in creating and maintaining age and gender distinctions in North American society. Of course, clothing, tools, and leisure goods (we could add food, durables such as furniture and appliances, and the media) symbolize child/adolescent/adult distinctions and male/female distinctions. But reflection will suggest that they also actively construct these distinctions by socializing persons and by forming the sensible context of daily life which makes traditional age and gender roles appear to be natural. Grant McCracken (Culture $\mathrm{xv}$ ) has suggested, in fact, that the embodiment of gender roles in physical objects is one barrier to the alteration of those roles. Any man who has tried to teach a woman to change a tire, or woman who has given her husband a lesson in which kitchen appliances to use in which circumstances can verify the enormous investment in time and effort that each has put into mastering the tools of the gender trade. Gender differentiation in household work roles is objectified, not only symbolically expressed, in consumer goods.

To present the concept of objectification at the personal level, we can speak in psychological terms of aspects of the self being routinely projected onto material objects. That is, individuals use or focus on particular objects so as to satisfy felt needs. In order to understand specific instances of objectification on this individual level, we still need the anthropological perspective, that is, we need to know the cultural significance of goods and the social context of the individual. The meaning of the purchase of a speedboat, for example, is comprehensible only by integrating cultural symbolism, social circumstance, and individual psychology.

Like children playing with toys, or an artist seeking to convey sentiment through paint and canvas, or a scholar writing in order to think through a problem, the projection of aspects of the self onto the acquisition and use of material goods is purposeful. By making "felt needs" concrete, the individual establishes the potential of managing them. The ideal outcome of the process is then to reassimilate the objectified concerns into a larger, more complex, more mature self. This is a psychological version of the dialectic: by setting space between two propositions, the stage is set for integrating them into a larger whole. By objectifying aspects of the self, it becomes possible to gain perspective, consciously to use symbols, and ultimately to establish control over and integrate these aspects into a more highly developed self.

It is easiest to see this process where it is problematic aspects of the self that are objectified. For example, some cases of overeating can be represented as compensatory behavior, with food representing (in American culture) the love, caring, and self-indulgence that the individual needs. Objectifying these qualities onto food allows the individual to provide himself or herself with the needed doses of affection and care. Solving the psychological problem reduces the need for food as a fetish of self-indulgence, as the subject learns to draw instead on inner sources of comfort and self-esteem. We might think of this process as a sort of self-help therapy. As desired qualities are objectified, we create the potential of actually assimilating the qualities into ourselves. Purchasing expensive cars, furnishings, and leisure goods, for example, is (again, in American culture) a symbol of one sort of success. Ownership of such items may eventually allow the purchaser to feel genuinely successful and in time may actually serve to decrease, rather than increase, his or her dependence on objectified symbols of financial achievement.

But it would be misleading to think of the process of objectification as primarily pathological. In fact, it is a natural process of growth. Since, as human beings, our lives are bound into a social and material context, we grow only in that context. And, just as our personal development depends on human social interactions-we grow into independence, learn to love, to cooperate, to resolve conflicts-so it also depends on our interaction with material goods. Independence, for example, means survival in a physical, as well as a psychic, sense. Love, cooperation, and problem solving are displayed and developed by the use of material resources.

The use of material goods for nonmaterial human purposes is seen most easily (as Miller, following Jean Piaget and Melanie Klein, suggests) by observing children's use of toys in play. The child uses toys deliberately as symbols of real concerns. By enabling the child to organize and manipulate these concerns as concrete objects, the toys become tools for growth. The same process characterizes adult relations with possessions, but since the relations are implicit and largely unrecognized, the results, in terms of personal growth, are unpredictable. Like a growing child's toys, the things that surround us play a role in our development. But since we are largely unconscious of this, they act sometimes to assist and sometimes to impede us, willy-nilly. Yet every interaction with material goods provides an opportunity to use the natural processes of symbolization, objectification, and reassimilation to assist our 
spiritual growth.

\section{Theory into Practice: Using Goods for Spiritual Development}

We have seen that objects, like people, have a dual nature. Human beings are physical and spiritual; objects are material and symbolic. Recognizing the meaning of an object, distinct from its physical qualities, permits us to assess its significance to our spiritual nature, beyond our physical use of it. To return to the laboratory or schoolroom metaphor, we can use material goods as tools to stretch our spiritual selves.

Because of the ingrained Western habit of thinking in terms of spiritual/physical dualism, it is necessary to emphasize that material goods, in themselves, are for the most part morally neutral. In Bahá'í philosophy, we do not leave behind the material world in order to become spiritual. Personal spiritual growth depends not on the simple presence or absence of things, or even on their nature, but in how they are used by the individual. A quotation from 'Abdu’l-Bahá suffices to affirm this point:

In this day or dispensation asceticism is of the spiritual type, for spiritual asceticism is right and is productive of results.... In this dispensation there is no physical or material asceticism. (Star of the West 6061)

Spiritual asceticism is a difficult concept for those reared in a culture that radically separates the physical and the spiritual. 'Abdu'l-Bahá's statement indicates that it is not the abundance or lack of material possessions that determines our attachment to worldly things. Rather, it is our attitude that is critical; we are enjoined to be detached "in the spirit" rather than "in the flesh." One person may be desperately attached to a paltry stock of possessions; another is able to walk away from a fortune without regret when spiritual concerns require it.

Bahá'í writings repeatedly assert the obligation for Bahá'ís to engage in remunerative work, to excel at their professions, and actively to utilize material resources to further human progress. In addition to these religious exhortations, Bahá'ís living in the West find themselves obliged by the nature of their society to engage in constant, massive, and demanding interaction with physical objects. We are thereby provided with a profound challenge to live a spiritual life within the highly materialized life in which we find ourselves. 'Abdu'l-Bahá's remark that "spiritual asceticism" is "productive of results" indicates that the proper response to this challenge will result in real benefits for us. I suggest that by recognizing the symbolic dimension of material goods, we can use them for spiritual growth by deliberately managing processes of objectification and reassimilation.

The role of material goods in personal development is intrinsic to human life and so is a constant source of either obstacles or aids to spiritual growth throughout our lives. Children use toys to move through developmental stages: to become more independent, to work through fears, to learn cooperation. Adolescents in the American culture engage with consumer goods as a means of negotiating the paradox of conformity and individualism central to the American definition of an adult. To consider only one dimension of adult life, women in the United States use goods to develop a representation of self that depends strongly on predominant cultural notions of appearance, while men use them to explore cognate gendered cultural notions of economic success. All human beings use goods throughout our lives, depending on their tremendous symbolic capacity to aid us to form relationships, develop our personality, and achieve our visions of a good life.

Conscious attention to the symbolic dimension of material goods opens to us several sorts of opportunities for spiritual growth. By recognizing when our acquisition or use of goods is an objectification of problematic aspects of the self, we can take steps to rise to a higher level of perception, overcome the problem, and reassimilate the objectified qualities. Also, we can use goods as explicit challenges, which in concrete physical form stimulate the inner self to grow-for example, by learning a handicraft to develop patience and creativity, subscribing to an international magazine to increase worldmindedness, or wearing more formal clothes than usual to encourage a sense of respect. And goods obviously carry objectified meaning which can assist us in maintaining rewarding human relationships. By attending to the message-bearing capacity of goods, we can use them to foster harmonious and progressive human relations, for example, by providing support for our family, gifts for friends, hospitality for guests and by public philanthropy.

If things are not used in this way, as tools for personal development, they can-and perhaps inevitably will-block growth. Material goods, because of their prevalence and symbolic potential, are easily misused. If the meanings that they objectify are not reassimilated, they inhibit progress - and they have potential even to reduce the maturity and complexity of the individual. This is a very frequent result of the acquisition and use of material goods in mass consumer culture, where objects flood the message marketplace, and it becomes almost impossible to distinguish the message from the object itself. (Advertising aggravates this, since it radically separates the meaning of an item from its physical nature; the persuasiveness of advertising thus permits self-referential messages of "success" or "pleasure" to be attached to a plethora of consumer goods.) The end result of this process is that objects insidiously take the power of meaning away from people and reserve it to themselves. At first, we might say, a BMW is a sign of success. In the next stage, a person who owns a BMW is perceived as, and assumed to be, a success. Eventually, it becomes impossible to be a success (in your own eyes or anyone else's) unless you have a BMW. The power to define” success,” in this simple example, has shifted from people to things.

In mass consumer culture, a human quality such as love or joy moves out of the realm of human interaction 
and becomes fixed in objects. For example, “joy” is casually redefined as "pleasure” in public representations, and we come to expect to find it in the acquisition and use of material things. People lose the ability to recognize the symbolic dimension of goods, and come to see abstract qualities as actually inhering in objects ("Coke," for example, "is life”). The negative result of objectification (identified by Marx) is that it denies the primacy of human qualities, replacing it with the primacy of material objects. It gives objects the capacity to create meaning, which is rightly the task of human intellect, emotion, and will. This is the source of the pervasive dissatisfaction with materialism in Western culture, since goods are continually presented to us as the source of significance, whereas in fact they are only the bearers of humanly created significance. This, then, is the dangerous potential of objectification, wherein the relationship between goods and persons is distorted.

Is this what 'Abdu'l-Bahá meant when he said, "Detachment consists in refraining from letting our possessions possess us" (Star of the West 63)? I think it is at least part of it. In an elaborated restatement of a theme common to the world religions, Bahá'í philosophy explicitly accepts and appreciates the material world but constantly cautions us not to be attached to it.

By being severed from the world I do not mean holding in contempt the things of the world, for civilization and education are the means of progress. I mean that one must not attach his heart to the world. ('Abdu'lBahá, Star of the West 63)

I wish for the happiness and prosperity of the believers even in this material world, but they must not be attracted by it or attached to it. Extreme wealth or utter poverty should be equal to them. (65)

This is a very difficult state to achieve. It is made more difficult by the materialistic context of life in industrialized societies and by the popular philosophies of material goods traditional to Western culture. Notions of the spiritual life as physically ascetic, of sacrifice as deprivation, and of material success as ungodly, hamper our efforts to be simultaneously appreciative of God's bounty and detached from it. Understanding the psychological, social, and cultural processes that organize human dealings with material goods provides us with tools we can use in learning to deal spiritually with the material aspects of our lives.

\section{Notes}

1. The study of the symbolic meaning of goods in industrial societies is, except for a few early efforts such as Veblen's, still in its infancy. Significant recent efforts, in addition to those of Miller, are by: Douglas and Isherwood, The World of Goods; Appadurai, The Social Life of Things; Csikszentrnihalyi and Rochberg-Halton, The Meaning of Things; McCracken, Culture and Consumption; Scitovsky, The Joyless Economy.

\section{Works Cited}

‘Abdu’l-Bahá. Star of the West. Vol. 8. No.6. June 24, 1917.

Appadurai, Arjun, ed. The Social Life of Things: Commodities in Cultural Perspective. Cambridge: Cambridge University Press, 1986.

Csikszentmihalyi, Mihaly, and Eugene Rochberg-Halton. The Meaning of Things: Domestic Symbols and the Self. Cambridge: Cambridge University Press, 1981.

Douglas, Mary, and Baron Isherwood. The World of Goods: Towards an Anthropology of Consumption. New York: W.w. Norton, 1979.

Hatcher, John S. The Purpose of Physical Reality: The Kingdom of Names. Wilmette: Bahá'í Publishing Trust, 1987.

McCracken, Grant. Culture and Consumption: New Approaches to the Character of Consumer Goods and Activities. Bloomington: Indiana University Press, 1988.

Miller, Daniel. Material Culture and Mass Consumption. Oxford: Basil Blackwell, 1987.

Scitovsky, Tibor. The Joyless Economy: An Inquiry into Human Satisfaction and Consumer Dissatisfaction. New York: Oxford University Press, 1976. 